\title{
Uma redefinição do teatro político
}

\begin{abstract}
Patrice Pavis ${ }^{1}$
Tradução: Mônica Gama²

\section{Resumo}

O presente texto foi escrito para de dialogar com o livro Théâtres du Réel en Angleterre et en Ecosse, de Daniele Merahi, que deve ser lançado no ano de 2014. O autor propõe, em sua reflexão, o teatro documentário como um teatro político.
\end{abstract}

Em seu livro, Danielle Merahi se concentra no que chama de "teatros do real." Essa noção permite redefinir o teatro documentário e político centrado na observação da realidade, associando-o a autores (Caryl Churchill, David Creig), diretores ligados ao teatro político (Ewan MacColl), popular (John McGrath) ou comunitário (Peter Cheeseman), praticantes do devised theatre (Simon McBurney), coreógrafos (Lloyd Newson e seu grupo DV8) ou ainda defensores do teatro documentário verbatim (Alecky Blythe).

A enumeração à la Prévert poderia surpreender se os argumentos e as análises de Danielle Merahi não demonstrassem precisamente que todas essas diferentes empreitadas nos ajudam a melhor compreender o real. Não são mais os efeitos de real e o realismo que qualificam esses teatros do real, mas a possibilidade de construir e explicar o real a partir dos procedimentos artísticos de determinadas obras. Graças ao olhar distanciado da autora, surge uma nova face do teatro, uma face oculta, mas emocionante. Nessa abordagem, o avesso do teatro não é a ilusão, a ficção, a teatralidade, mas a vida social, a política, a luta de classes, a sobrevivência econômica e o cotidiano.

Um livro sobre as diversas facetas do real é muito oportuno. Ele nos convida a olhar, para além das fronteiras francesas e europeias, como o teatro restabelece

\footnotetext{
1 Patrice Pavis: é professor de estudos teatrais na University of Kent, Canterbury, Inglaterra. Sua extensa obra versa sobre temas como Performance, semiologia e interculturalismo.
2 Mônica Gama é doutora em Literatura Brasileira pela Universidade de São Paulo e sua pesquisa focaliza o processo de criação literário de João Guimarães Rosa. Em parceria com Claudia Amigo Pino, é editora de números das revistas Manuscrítica e Criação \& Crítica.


relações com o real e o político. Os artistas mencionados no estudo não temem sujar as mãos na graxa das engrenagens sociais, da economia globalizada, da miséria do mundo. Eles colocam o dedo na ferida da engrenagem social. Se criam um teatro pobre, não é no sentido estético ou antropológico de um Tadeusz Kantor ou de um Jerzy Grotowski, mas de um teatro que trabalha em condições precárias, feito à imagem das pessoas cujas vidas cotidianas são por ele retomadas.

Segundo a teoria clássica da mimesis, o teatro deve mostrar a realidade diretamente e com precisão. Definida pela primeira vez por Aristóteles, essa mimesis significa muitas coisas: representação, imitação, semelhança, verossimilhança. Em torno do final do século XIX, pouco antes do modernismo, o realismo pretende reconstituir o real e registrar o mundo como ele é, tão feio e cru quanto for. Nesse caso, o teatro apenas assegura o verdadeiro e o verossímil. No entanto, com a chegada concomitante da encenação e do modernismo, o teatro (por exemplo, o teatro simbolista) insiste na constituição formal da representação, e tende a se voltar sobre si mesmo, sem se referir diretamente à realidade. Da mesma forma, o pós-modernismo nos anos 1950 e 60, e depois o pós-dramático na década de 1970, desconfiam da referência à realidade. Mas desde os anos 1990 tem havido, nas artes plásticas e no teatro, um retorno do real, sem que esse retorno se dê em relação à totalidade da representação, como Hegel, Marx e Lukács reivindicaram anteriormente. O ressurgimento da realidade nas artes plásticas não ocorre por acaso. É um pouco o retorno do reprimido. Até os anos 1980, reinou um teatro virtuoso e brilhante, centrado nas invenções da encenação, sem refletir muito sobre seu afastamento gradual do mundo social. A chegada do culturalismo e do tout-culture ${ }^{\beta}$, o desenvolvimento dos estudos da performance, responsáveis por abordar todos os tipos de performances culturais, precipitaram o fim do político em favor do cultural, do humanitário e do compassivo. Esse retorno do referente social ou político vem acompanhado pelo prazer de contar e ouvir histórias, de apreciar o sentido dramático de uma fábula bem construída, de uma narrativa bem conduzida e de reconhecer um universo familiar. Prazer ainda mais manifesto porque o público estava confuso e cansado do formalismo pós-moderno ou do virtuosismo vazio do pós-dramático.

Assim, com o retorno da realidade sócio-política, esse público poderia se expandir num piscar de olhos, uma vez que os temas, as programações e as orientações da

3 A expressão tout-culturel diz respeito a um movimento de globalização da cultura, de uma estratégia de abertura e legitimação de artes "menores", sacralizando-se criadores e criações em face ao desencantamento do mundo [N. do T.]. 
política cultural abririam o teatro à comunidade de amadores, estudantes, cidadãos comuns e grupos interessados diretamente nas questões socioculturais que desejavam ver abordadas no palco, participando, de alguma forma, de sua elaboração.

Em seu bem documentado livro, Danielle Merahi examina em detalhe as diferentes tendências desses teatros do real. Mostra a originalidade de cada forma ou de cada experiência. Sua tarefa é dupla: por um lado, identificar as obras e os gêneros que se expandem e nos abrem para a realidade; por outro, indicar que tipo de real aparece em cena e como o espectador pode acessá-lo.

Desde o início do novo milênio, o teatro está, novamente, assumindo o mundo. Esses reencontros com o real levam-nos de volta à política por caminhos muito diferentes daqueles de outrora: não mais como agit-prop ${ }^{4}$ ou grandes painéis históricos, mas por meio de formas concretas: investigações de campo, montagem de citações usadas literalmente, debates sócio-políticos dentro da representação. Assim se misturam discursos, pesquisas, aberturas para o mundo, que encontram, para cada caso particular, os meios teatrais ou performativos para expressar sua parcela da realidade.

Pode-se imaginar muitas outras formas possíveis de teatros do real, apenas combinando os parâmetros de diferentes experiências. Quase é possível acreditar que, com um pouco de otimismo ou ingenuidade, o teatro realista vá nos abrir as portas do real e nos explicar o funcionamento do mundo. No entanto, depois da teoria psicanalítica de Lacan sabemos bem que o real é o que sempre resiste à representação. Dizem que o real é o impossível ... mas o que acontece com o conhecimento do real social pelos meios do teatro? O que podemos aprender dos mecanismos da sociedade? Como ilustrar na cena questões sobre a política ou a financeirização da economia, como esclarecer processos cada vez mais complexos que escapam, em grande parte, até mesmo aos especialistas? A invenção formal de autores e diretores, artistas e ativistas pode tornar-se uma ferramenta ou uma arma temível?

Paradoxalmente, uma forma original, que se distancia de uma representação mimética realista, muitas vezes é mais eficaz. O realismo ou o naturalismo não são mais garantia para representar ou explicar o real. Mostrar o modo de vida das pessoas, supondo que seja representável no palco, não é satisfatório nem suficiente para tornar compreensível a situação psicossocial das pessoas (e não apenas figurá-la e senti-

4 Agit-prop é uma abreviação de agitação e propaganda, dois princípios do ativismo social ligados à disseminação do comunismo [N. do T.]. 
-la). Registrar suas palavras e suas imagens já não é prova de veracidade. A noção de realidade social distancia-se como uma miragem, ou pelo menos se redefine, quando os espectadores se aproximam dela do modo como surge na representação cênica ou dramática. O único critério de uma representação clara e justa da sociedade é saber se os espectadores sentem-se representados enquanto grupo que corresponde a essa representação, se o teatro dá conta de sua situação e se consegue esboçar uma solução para ela com os procedimentos da ficção. A escrita, mesmo a poética, por vezes é o melhor meio de acessar o real. A ficção, a artificialidade do jogo, a intensidade são necessárias para a descoberta de elementos do real e para a sua elucidação. O trabalho artístico e formal (mas não formalista) é uma etapa indispensável quando as formas e a dramaturgia esforçam-se para revelar conteúdos sócio-políticos ou psicológicos. A arte é, ou se torna, uma das melhores ferramentas para questionar a realidade e a política.

Aos exemplos ingleses e escoceses do livro de Merahi, o leitor poderá facilmente adicionar grupos alemães (Rimini Protokoll, She She Pop) ou franceses (L'avantage du doute, Superama) que se especializam em investigações sociais ou antropológicas. Muitas vezes documentos são citados, "especialistas" são chamados ao palco e convidados a expor suas análises. Eles falam, então, de modo mais ou menos improvisado, em seu próprio nome: como fizeram Marc Augé em 1973, de Massimo Furlan, Bernard Stiegler em Idiot cherche village, de Thomas Ferrand, assim como os especialistas do Karl Marx. Tome un [Karl Marx. Livro 1], do Rimini Protokoll. O espetáculo é um instante colocado entre parêntesis para que se ouça a opinião desses especialistas. Mas sempre há uma forma original e irônica de inserir, mais que servir, esses fragmentos de testemunhos autênticos, essas reflexões sobre a realidade social. No entanto, a questão permanece: o que queremos que esses documentos digam? Como sua apresentação, sempre dirigida e até mesmo desviada, contribui para influenciar os espectadores, para fazê-los mudar de opinião ou de estilo de vida? Para o indivíduo, essa busca do real é também, e acima de tudo, um modo de encontrar e reforçar a expectativa e a atenção sobre si e no outro, para não se tornar uma máquina, para manter o elo social.

O trabalho de Danielle Merahi, fundamentado e preciso, poderia servir de guia (ou ao menos de inspiração) nessa reconquista do real e dos meios de influenciar politicamente sobre ele. Quem não tem, como ela, a nostalgia do "prazer de ir ao 
teatro", para que a cena volte a ser esse lugar de encontro e conquista da palavra, esse espelho que reflete nossas vidas? Nesses tempos pós-modernos e pós-dramáticos, nesses momentos de desânimo sociopolítico, é preciso coragem para recusar as facilidades do teatro de entretenimento e de conforto, esse teatro que arrisca pouco e se conforma rapidamente à moda e ao mainstream. É preciso, em suma, a coragem de engajar a vida na recusa das injustiças, na confiança dos poderes da arte e na vontade irrepreensível de pensar sobre o real.

\section{Referências Bibliográficas}

MERAHI, Danielle. Théâtres du Réel en Angleterre et en Ecosse. Paris: Editions L'Entretemps (no prelo - lançamento previsto para 2014) 